\title{
Hipertexto como mediador pedagógico
}

\author{
Hypertext as pedagogical mediation
}

El hipertexto como mediador pedagógico

\author{
RODRIGO OTÁVIO DOS SANTOS Đa \\ Alvino Moser $\mathbb{D D}_{\mathrm{b}}$ \\ THEREZA LIMA
}

\section{Resumo}

O hipertexto é, por definição, uma forma de escrita/leitura não-linear e não hierarquizada que permite o acesso ilimitado a blocos de informação ligados a palavras, partes de um texto ou imagens. No presente artigo tentaremos abordar algumas questões acerca do hipertexto e da sua utilização no processo de aprendizagem. Assim, durante o texto que se segue, definiremos hipertexto, discutiremos a questão da mediação na aprendizagem e o hipertexto como importante mediador na contemporaneidade. Entretanto, para que o hipertexto possa ser um bom mediador, discutiremos carga cognitiva e a forma como os jovens digitais se comportam no momento do aprendizado. Assim, o objetivo deste artigo é trazer algumas reflexões que, acreditamos, merecem ser consideradas e analisadas, para um melhor entendimento do fenômeno da aprendizagem mediada no século XXI. A metodologia é de cunho bibliográfico, procurando em autores subsídios para fundamentar o hipertexto como mediador da aprendizagem. Serão considerados os aspectos referentes à carga cognitiva dos hipertextos. Os principais resultados de nosso artigo, que se trata de um ensaio teórico, buscam promover uma perspectiva crítica em relação à carga cognitiva nos/dos discentes. Também analisamos criticamente as questões pedagógicas do hipertexto enquanto mediação para os jovens digitais.

Palavras-chave: Hipertexto. Carga Cognitiva. Mediação no ensino-aprendizagem.

\footnotetext{
a Centro Universitário Internacional (UNINTER), Curitiba, PR, Brasil. Doutor em História, e-mail: rodrigoscama@gmail.com

b Centro Universitário Internacional (UNINTER), Curitiba, PR, Brasil. Doutor em Ética, e-mail: moser.am@gmail.com

c Centro Universitário Internacional (UNINTER), Curitiba, PR, Brasil. Doutora em Letras, e-mail: thereza.l@uninter.com
} 


\begin{abstract}
Hypertext is, by definition, a non-hierarchical, non-linear form of writing / reading that allows unlimited access to blocks of information linked to words, parts of text or images. In this paper, we will try to address some questions about hypertext and its use in the learning process. Thus, during the text that follows, we will define hypertext; we will discuss the question of mediation in learning and hypertext as an important mediator in contemporaneity. However, for hypertext to be a good mediator we will discuss cognitive load and the way digital youngsters behave at the time of learning. Thus, the objective of this article is to bring some reflections that, we believe, deserve to be considered and analyzed, for a better understanding of the phenomenon of learning mediated in the 21st century. The methodology is of a bibliographic nature, looking for authors in subsidies to base the hypertext as a mediator of learning. The aspects related to the cognitive load of hypertexts will be considered. The main results of our article, which is a theoretical essay, seek to promote a critical perspective regarding the cognitive load in the students. We also critically analyze the pedagogical issues of hypertext as mediation for digital youth.
\end{abstract}

Keywords: Hypertext. Cognitive Load. Pedagogical Mediation.

\title{
Resumen
}

El hipertexto es, por definición, una forma de lectura/escritura no lineal y no jerárquica que permite el acceso ilimitado a los bloques de información unidos a las palabras, partes de texto o imágenes. Desde la comunicación oral a la comunicación por medios digitales, los medios se estaban volviendo cada vez más complejo, y el lenguaje textual también tuvo una significativa evolución. En la actual era del conocimiento, en la cual es natural la sobrecarga de información, la narración adquiere una estructura hipertextual, como forma de organización en red, facilitando la interacción de los textos para una búsqueda más rápida de la información, pero sin causar, en algunos casos, un exceso de carga cognitiva para los usuarios. El propósito de este artículo es traer algunas ideas que creemos que merecen ser tratadas y analizadas, como es el caso de la mediación pedagógica en los entornos de hipertexto. La metodología es de cuño bibliográfico buscando en autores subsidios para fundamentar el hipertexto como mediador del aprendizaje. Se considerarán los aspectos referentes a la carga cognitiva de los hipertextos. Los principales resultados de nuestro artículo, que se trata de un ensayo teórico, buscan promover una perspectiva crítica en relación a la carga cognitiva en los discentes. También analizamos críticamente las cuestiones pedagógicas del hipertexto como mediación para los jóvenes digitales.

Palavras clave: Hipertexto. Carga cognitiva. Mediación pedagógica. 


\section{Introdução}

O hipertexto, termo criado por Theodore Nelson, na década de 1960, é, por definição, uma forma de escrita/leitura não-linear e não hierarquizada que permite o acesso ilimitado a blocos de informação ligados a palavras, partes de um texto ou imagens.

A comunicação sempre foi, ao longo da história da humanidade, um fator determinante para o desenvolvimento da inteligência humana, como já informa Mattelart (2007). Inicialmente, os seres humanos se comunicavam apenas por meio da linguagem oral. Esta forma de comunicação permitiu aos homens saírem das cavernas e das árvores, onde habitavam, para viver em comunidade, explorando os recursos que a natureza lhes oferecia.

Todavia, como salienta Michael Polanyi (1966 p. 4), "nós sabemos mais do que podemos expressar oralmente". Assim sendo, um fator fundamental para o desenvolvimento da inteligência humana foi a invenção da escrita. Esta evolução permitiu à humanidade uma melhor compreensão da realidade na qual ela estava inserida, levando-a ao desenvolvimento de suportes mais adequados para a sua comunicação e para as suas representações gráficas. Nesse sentido, o conhecimento desenvolvido por uma determinada civilização passou a ser transferido, de uma geração para outra, de forma codificada e explícita, permitindo um acúmulo significativo de conhecimentos ao longo dos anos. Este fator explica, de certo modo, o grande poder da Igreja Católica na Idade Média, pois os "papiros" com os conhecimentos desenvolvidos pela humanidade, ao longo dos tempos, estavam em grande parte em seu poder, nos mosteiros.

No Século XV, ocorre um fator extremamente relevante para o desenvolvimento da inteligência humana: o desenvolvimento da prensa de tipos móveis pelo inventor e gráfico alemão, Johannes Gensfleisch zur Laden zum Gutenberg. A impressão permitiu que a humanidade saísse do "obscurantismo"4 da Idade Média e, gradativamente, entrasse no Renascimento, com o desenvolvimento das artes plásticas, cênicas, musicais e, sobretudo,

\footnotetext{
${ }^{4}$ Não é universal a crença de que a Idade Média tenha sido uma era do "obscurantismo", como estudiosos, por exemplo. Fernand Van Steinberger, Etienne Gilson, Frederic COPLESTON, Paul Vignaux e outros.
} 
da literatura, tal como a conhecemos hoje. O texto impresso foi o paradigma da comunicação humana nos séculos seguintes (XVI, XVII, XVIII, XIX e XX). É evidente que houve uma evolução significativa nos processos de impressão ao longo desses séculos. De um processo de impressão em massa de tipo móvel, com a utilização de uma prensa de madeira similar à prensa de parafuso agrícola do século XV, ao processo de impressão baseado em rotativas de impressão off-set do século XX, houve sem dúvida uma inovação, mas do tipo incremental, pois a ciência de base que suportava a tecnologia da impressão não se modificou. Somente no final do século XX é que vai ocorrer uma revolução na linguagem textual, com o advento da Internet, como já mostra Castells (2003). Essa inovação certamente traz consigo inúmeras alterações também no campo didático.

O presente trabalho visa analisar o hipertexto como mediador pedagógico na perspectiva de autores que dele tratam. Esta análise se faz necessária porque o hipertexto, tão comumente visto como "solução" ou "evolução" pode ter em sua elaboração demasiados envios a links, envios estes que sobrecarregam a capacidade de compreensão do leitor ou dos estudantes, e dificulta a interpretação do texto. Poderá este excesso exceder a carga cognitiva do leitor ou do estudante? Isso porque na era do conhecimento, com o excesso de informações, a narrativa ganha estrutura hipertextual, com forma de organização em rede, facilitando a interatividade entre textos, necessária para a busca da informação com mais rapidez, mas que, em alguns casos, sobrecarga a cognitiva para seus usuários.

\section{O hipertexto}

É muito difícil escrever algo sobre hipertexto, que já não tenha sido tratado por algum autor, haja vista que se consultarmos o termo no Google, este nos apresenta mais de 1.310.000 resultados. O objetivo deste artigo é trazer algumas reflexões que, embora não tenham o selo de originalidade, merecem ser lembradas e consideradas. Talvez haja algum matiz ou viés, que mereça a atenção.

As definições do termo hipertex to indicam ser um texto, característico da linguagem do ciberespaço diferente da linearidade e logicidade da maioria dos textos rígidos, apresentados nos escritos físicos. Pierre Lévy (2008, p. 92) apresenta sua definição de ciberespaço: 
Eu defino o ciberespaço como o espaço de comunicação aberto pela interconexão mundial dos computadores e da memória dos computadores. Esta definição inclui o conjunto dos sistemas de comunicação eletrônicos (aí incluídos os conjuntos de redes horizontais e telefônicas clássicas), na medida em que transmitem informações provenientes de fontes digitais destinadas à digitalização. Insisto na codificação digital, pois ela condiciona o caráter plástico, fluido, calculável com precisão e tratável em tempo real, hipertextual, virtual, da informação que é, parece-me, a marca distintiva do ciberespaço.

Note-se que em sua definição, Lévy evoca o caráter de hipertextualidade das informações e torna estes textos plásticos, fluidos, gerando um espaço em que qualquer pessoa pode ter acesso livremente, um espaço aberto para a exploração dos indivíduos. $\mathrm{O}$ hipertexto é, pois, uma forma de escrita que possibilita ao leitor e estudante escolher alguns caminhos ou trilhas, a partir de associações e inserções ou remissões às quais o texto envia de modo não linear. As inserções, links e remissões a outros textos possibilita acesso imediato, sem a necessidade de busca em sites relacionados e enriquecem o caráter semântico das proposições hipertextuais. Como apropriadamente afirma Xavier (2005, p. 170) a respeito, o texto na internet possui forma híbrida, dinâmica e flexível de linguagem que dialoga com outras formas semióticas, que adiciona e acondiciona outras formas a sua superfície, outras formas de textualidade. Além disso, possibilita a leitura com coprodução de textos e de hipertextos.

Há, assim, um diálogo no próprio hipertexto, um diálogo entre os seus elementos, os constituintes remetendo-se uns aos outros, de forma a possibilitar não apenas a compreensão do exposto, mas a coprodução pelo próprio leitor. Em outros termos, a forma hipertextual exige um leitor ativo, construtivo e criativo, incitando-o a exercer sua imaginação de uma maneira diversa do leitor que usa a imaginação apenas por meio do texto linear.

É uma forma de linguagem e de comunicação multimodal e possibilita ao leitor a abertura imediata a ideias correlatas e conexas, podendo ampliar assim o leque de possibilidades de significado. Alarga o campo semântico trazendo informações, dados, links, vídeos e demais formas de informação para que o leitor possa ter mais compreensão e, ao mesmo tempo, fornece recursos para uma co-construção do significado.

É condição imprescindível que a linguagem hipertextual seja interativa, característica própria de uma linguagem digital, superando a linearidade da escrita impressa, como o são as notas de rodapé e outras remissões. A este respeito, conclui Monteiro (2016 p. 22): 
Juntamente com o conceito de não linearidade no hipertexto vem o princípio de interatividade, premissa não verdadeira para o texto impresso, apesar de este ter conexões, porém conexão não é necessariamente sinônimo de interatividade.

Os hipertextos podem facilitar ao leitor a recuperação das informações e subsídios de maneira instantânea e, quando o estudante se propuser, pode ele fazer novas conexões para "ressignificar" o texto, moldando-o ao seu modo, imprimindo-lhe uma nova configuração.

O que diferencia o conceito de hipertexto dos documentos impressos é que no hipertexto "a informação encontra-se de fato, armazenada em uma rede de nós conectados por ligações” e podem ser nós contendo gráficos, textos, sons e imagens; são documentos "hipermídiáticos". "As ligações unem essas entradas entre si: do texto lido aos textos a ler, da ilustração ao trecho de música. É sempre possível modificá-los, ao contrário do documento impresso" (LE COADIC, 1996, p. 60).

0 texto [do hipertexto] apresenta-se fragmentado, atomizado em seus elementos constitutivos (em lexias ou blocos de texto), e essas unidades legíveis passam a ter vida própria ao se tornarem menos dependentes do que vem antes ou depois na sucessão linear (LANDOW, 1992, p. 52).

O hipertexto, de certa forma, simula a mente humana na organização da memória como uma rede semântica em que os conceitos estão conectados por associação. Esta ideia lembra a afirmação de McLuhan (1996), segundo a qual os meios são extensões do homem.

O hipertexto permite construções variadas e diversas de indivíduo a indivíduo, pois o cérebro não procede linearmente, mas de maneira selecionista (EDELMAN, 2007), ou seja, seleciona, segundo sua evolução no nicho eco-sócio-cultural quais os caminhos julgados melhores para a compreensão das informações, bases para a tomada de decisões. As conexões hipertextuais podem ser consideradas como paralelas às conexões neuronais, sendo, porém de outro gênero e de outra espécie de complexidade. Além do mais, as conexões e nós encontrados nos hipertextos são programados pelo autor do texto, ao passo que o cérebro do leitor não é programável (EDELMAN, 2007), tampouco temos a certeza dos caminhos que cada estudante pode tomar.

Uma vez que o produtor do texto eletrônico é quem decide disponibilizar ou não links com outros hipertextos afins. E esses links hipertextuais podem apenas respaldar o ponto de vista do seu autor, embora a transparência das ideias e posições seja um traço inerente à própria concepção da rede informacional (XAVIER, 2005, p. 173). 


\section{A mediação na aprendizagem}

A aprendizagem é uma atividade que se processa em primeira pessoa, pois exige a apropriação consciente das informações. Mas a aprendizagem não é uma atividade totalmente imanente, isto é, fruto apenas das atividades do sujeito aprendiz. Pode-se aprender por reflexão, de maneira subjetiva e imanente; pelas informações advindas dos sentidos (sense data), pela conversação e diálogo e, enfim pela leitura, que pode ser comparada a um diálogo com o ausente, como já o observara Descartes (1953). Experiência, diálogo e leitura são mediações, e a mediação na aprendizagem remete aos estudos de Vygotsky.

Vygotsky (1991) considera a mediação na perspectiva marxista e refere-se especificamente ao trabalho. Para executar o trabalho, o homem usa instrumentos, o meio pelo qual o homem transforma a natureza: o meio pode ser uma enxada, uma pá, ou as agulhas de tricô. Esses exercem a função de mediação ou segundo Martha Kohl de Oliveira (2002. p. 26) "Mediação [...] é o processo de intervenção de um elemento intermediário numa relação; a relação deixa então de ser direta e passa a ser mediada por esse elemento”. Acrescenta ainda "a mediação é um processo essencial para tornar possíveis as atividades psicológicas”. Para Vygotsky (apud Oliveira 2002), a aprendizagem se processa, como para quase todas as ações humanas, por meio de uma mediação, podendo ser semiótica, escrita ou falada, ou por outros meios: livros, filmes, vídeos entre outros. De fato, o ser humano não tem acesso direto aos objetos do mundo real, no qual ele está inserido, mas um acesso mediado pelo conceito processado na mente.

O signo, por outro lado, não modifica em nada o objeto da operação psicológica. Constitui um meio da atividade interna dirigida para o controle do próprio indivíduo; o signo é orientado internamente (VYGOTSKY, 1991, p. 62). Não devemos esperar encontrar muitas semelhanças entre os instrumentos e aqueles meios de adaptação que chamamos signos. E, mais ainda, além dos aspectos similares e comuns partilhados pelos dois tipos de atividade, vemos diferenças fundamentais, pois os signos pertencem à linguagem e representam objetos e conceitos para seu interpretante.

Portanto, a construção do conhecimento é uma interação mediada por várias relações (sujeito-sujeito e sujeito-objetos), ou seja, o conhecimento não é entendido como 
uma ação do sujeito cognoscente sobre a realidade, como salienta a abordagem construtivista, mas pela mediação feita na qual outros sujeitos ou meios interferem.

Contudo, convém ressaltar que, mesmo na reflexão ou quando aprendemos pela intuição das ideias claras por si mesmas, existe a mediação semiótica, pois as ideias nos vêm por palavras ou imagens mentais. Mediação semiótica é um conceito segundo o qual o ser humano consegue interpretar o que o rodeia. E para tanto, utiliza-se da linguagem. Não há como pensar se não utilizarmos palavras ou imagens. A mediação pela linguagem é uma mediação semiótica. Marta Kohl de Oliveira (1992 p. 42) ao tratar da aprendizagem em Vygotsky afirma que: “a principal função da linguagem é a de intercâmbio social: é para se comunicar com seus semelhantes que o homem cria e utiliza os sistemas de linguagens".

Segundo Shechtman (2009), a mediação pedagógica é um processo comunicacional, também conversacional, com construção de significados, cujo objetivo deve ser ampliar as possibilidades do diálogo e desenvolver a negociação significativa de processos e de conteúdo a serem trabalhados nos ambientes educacionais, bem como incentivar a construção de um saber contextual, relacional, gerado na interação professor-aluno.

A mediação pedagógica pressupõe, portanto, a ação de um professor ou "mediador", seja em ambiente presencial ou virtual, para desenvolver no aluno a curiosidade, a motivação, a autonomia e o gosto pelo aprender.

\section{O hipertexto como mediador da aprendizagem}

A aprendizagem, de modo simples, é uma mudança de comportamento que não é fruto da maturação. Mayer (1982 p. 1040) define aprendizagem como "uma mudança relativamente permanente no conhecimento ou no comportamento de uma pessoa de devido à experiência”. Para Driscoll (1994, p. 8), a aprendizagem é resultado da interação com o meio ambiente: “aprendizagem é uma mudança persistente no desempenho humano ou no potencial de desempenho (trazido) como resultado da interação do aprendiz com o ambiente".

A mediação se torna de capital importância ao se tratar do ensino-aprendizagem dos jovens nativos digitais. Estes jovens querem autonomia e liberdade no modo e no tempo 
em que querem aprender. Beata Gofron (2014, p. 132) assinala que a escola precisa atentar ao fato de que a geração depois da web 2.0 não são mais passivos:

A Web 2.0 faz do usuário um participante interativo na ação, aquele que pode alterar o conteúdo e a forma dos anúncios. Internautas criam diálogos ativos com informações; não só os recebem, também questionam, seguem instruções e constroem respostas. Não são mais usuários passivos da rede da Web 1.0, mas usuários interativos da rede da Web 2.0. 0 modelo Web 2.0 permite ao usuário do serviço, como seus autores, moldar dinamicamente a imagem geral do conteúdo.

Este contexto provoca a mudança da função de professor; "não é mais o que fala do estrado, mas o que está ao lado do aluno no processo de aprendizagem" (LEBRUN, 2013). O docente é o mediador a propiciar aos seus estudantes condições para que haja a individualização e autonomia da aprendizagem. Ora, a natureza associativa e intuitiva do hipertexto suscita a interatividade e co-construção do texto e da aprendizagem assumida em primeira pessoa pelos alunos.

O alto grau de controle por parte do estudante é que faz do hipertexto um ambiente de aprendizagem tão bom ou melhor do que a sala de aula (LANDOW, 1997). O usuário/aluno, mediante a um grande número de conexões de formatos variados e de conexões dinâmicas tem a possibilidade de selecionar o material baseando-se em critérios como, por exemplo, o interesse pessoal, curiosidade, experiência, necessidades de informação ou tarefas demandadas.

O hipertexto constitui uma boa ferramenta de aprendizagem já que, de acordo com Laufer (1993), inclui os três tipos de aprendizagem propostos por Lewis e Spencer (1986): aprendizagem não ativa, em que se utiliza o mouse em ações físicas como apontar ou arrastar; representação icônicas e outras representações gráficas na tela, assim como a habilidade para acessar vídeos fixos e em movimento; e representações simbólicas, que incluem o uso de textos na tela assim como programas hipermídia produzidos pelo hipertexto. Assim, existem basicamente dois tipos de hipertextos:

De Realidade Simulada — quando se constrói hipertextos a serem explorados;

De Realidade Aumentada — quando se cria anotações e difundem-se informações associadas aos espaços que existem fisicamente.

Em ambos os casos podemos ter um mundo "imitado" e "controlado", dependendo apenas da construção do designer. Mas isso não significa que o aluno consiga identificar estes controles ou limitações. Há também sistemas em que novos links podem ser criados 
pelos usuários, o que os torna imprevisíveis e impossíveis de controlar, como é o caso das coleções alteráveis de documentos on-line chamadas Wikis.

\title{
Condições para que o hipertexto seja mediador
}

Para que haja interatividade no hipertexto é necessária a ação do aluno, que pode se portar passivamente ou ativamente. A interatividade supõe que o leitor ou aluno siga as trilhas como são propostas pelo hipertexto, modificando-as, contudo, segundo suas necessidades, segundo seu ritmo e seus objetivos. O aluno deve construir seu conhecimento e aprendizagem.

Logo, as construções de hipertextos precisam ser bem estruturadas e planejadas para a finalidade pedagógica.

\begin{abstract}
Afirmar que o hipertexto é deslinearizado não equivale a dizer que ele seja um conjunto de enunciados justapostos linearmente, um mosaico de frases randômicas. 0 hipertexto apresenta um maior distanciamento das formas tradicionais de hierarquizações por ser mais flexível na sua formatação visual, estocagem do material discursivo e, sobretudo das unidades de informação. Todavia, para ser inteligível, o hipertexto - como qualquer outro - precisa apresentar alguma linearidade, pois não pode subverter os níveis de organização das línguas naturais (sintaxe, semântica, pragmática) utilizada por uma dada sociedade. (XAVIER, 2005 p. 175)
\end{abstract}

\section{Hipertextos: observações críticas — carga cognitiva}

O hipertexto, por sua natureza e estrutura multimodal, oferece àquele que lê o alcance instantâneo de recorrer a um leque amplo de indicações semânticas, cognatas e correlatas que pode enriquecer a ação de pensar, de considerar muitas possibilidades, além de se valer da voracidade rítmica própria desses textos. Nesses textos digitais há uma ação de interatividade que permite ao leitor uma simultaneidade não encontrada em textos não digitais. Em outros termos, as possibilidades de espaços semânticos abertos pelo hipertexto se expandem exponencialmente com os recursos virtuais e digitais. Pierre Lévy (1996), diz que não se quer mais o pensar contemplativo diante de um autor ausente. Quer-se antes o texto que permita o pensar aqui e agora. Para Xavier (2006), esse imediatismo interacional, produto da crescente massificação do acesso à internet, acaba por incutir no usuário a modal necessidade de experimentar novas formas de linguagem afeitas a um querer dizer em rede mundial, sem o respaldo de um repressor inquisidor da norma linguística. Entretanto, na leitura dos hipertextos podem ocorrer vários obstáculos à compreensão. 


\title{
Excesso de carga cognitiva
}

Denomina-se carga cognitiva as informações coletadas, em certo instante, pela memória de trabalho. Ela determina a capacidade de processar informação e varia de pessoa a pessoa e tem influência na memória de longo prazo, sendo esta última a que determina a aprendizagem. É a fixação das informações para a execução de alguma tarefa ou para a compreensão de um texto. Se ao ler a terceira linha de um texto esquecemos da primeira, a memória de trabalho é muito baixa.

\begin{abstract}
Consideramos que a memória de trabalho é um sistema cerebral que fornece armazenamento temporário e manipulação das informações necessárias para tarefas cognitivas complexas como a compreensão da linguagem, leitura, aprendizagem, operações matemáticas, pensamento e raciocínio. A memória de trabalho está presente em várias tarefas diárias, como na manutenção temporária de um número de telefone, na resolução mental de cálculos matemáticos, quando seguimos direções e instruções, ao apresentarmos um trabalho, na leitura de um texto, ou seja, no momento em que a informação chega à mente, cabe à memória de trabalho manter durante segundos/minutos a informação que está sendo processada (PIPER, 2013).
\end{abstract}

Se for muito grande o fluxo de informações veiculadas pelo hipertexto, a memória não consegue processar, pois excede sua capacidade de armazenamento. O processamento das informações é feito pelas conexões e estas exigem tempo para serem fixadas. Esta capacidade também depende da atenção e muitas informações simultâneas ou que se sucedam muito rapidamente incapacitam o devido processamento. Diz-se, então, que há excesso de carga cognitiva. "Uma alta carga cognitiva amplifica a desatenção que experimentamos", afirma Carr (2011, p. 174) ao comentar os trabalhos de Torkel Klinberg. Excesso de informação produz a falta de concentração, logo da atenção.

A informação veiculada pelo hipertexto pode não ser computada por exceder a capacidade de memorização, pois esta é limitada (SQUIRE \& KANDEL, 2003, e excesso de informações não podem ser retidas na memória.

O hipertexto vem de encontro à capacidade multitarefa dos jovens digitais. Não constituirá um obstáculo à capacidade cognitiva do cérebro, (pois o cérebro pode executar várias tarefas simultaneamente, tais como ouvir música, e guiar automóvel), desde que não exceda a carga cognitiva própria de cada indivíduo.

Mas os links e hiperlinks podem sobrecarregar essa capacidade? Podem ocorrer duas situações: $O$ aumento de links pode auxiliar e capacitar o indivíduo a coletar mais 
rapidamente informações e favorecer a geração de esquemas que facilitem a aprendizagem para o conteúdo acadêmico. Por outro lado, o alargamento do leque de informações e estímulos pode ter impacto negativo no controle da atenção (UNCAPHER et al, 2015 apud BARBOSA, 2017).

O hipertexto, por exemplo, pode conter termos não constantes do vocabulário do estudante, assim como links estranhos ao leitor. Portanto, ao se elaborar um texto é preciso que se saiba o nível do aluno e sua capacidade, pois a busca do sentido de novos termos causará distração, como prova a pesquisa de Nicholas Carr (2011, p. 175). Segundo o autor, diante de uma floresta de hiperlinks se "está em uma situação em que ele vê a floresta, mas não distingue as árvores”.

Nicholas Carr (2011, p. 176 e 177) retoma os estudos de 1980 a 2000 sobre o tema. $\mathrm{Na}$ década de 1980 teciam-se aos hipertextos, mostrando a sua possibilidade em instrumentar o leitor para maiores e melhores esclarecimentos sobre um tema. Resumindo as discussões e contrastando com Landow e Delany, o hipertexto, afirma Carr (2011, p. 175-176.), tinham excessiva carga cognitiva. E os leitores acabavam a leitura distraídos e pouco se lembravam das informações lidas. Tal carga sobrecarrega o leitor, não permitindo que este possa se aprofundar devidamente nos assuntos, já que há limitações em seu próprio cérebro, segundo apontam as ciências neurocognitivas. Além de surfar entre links e hiperlinks, zapeando entre assuntos diversos, acrescentem-se os devaneios próprios das distrações normais de uma juventude propensa a dispersões máximas contra uma concentração mínima ou nula.

Carr também cita as pesquisas de Jean François Rouet e Jarmo J. Levonen (2011, p. 176 - nota de rodapé 20), segundo os quais, na medida em que os leitores ganhassem maior "intimidade com hipertextos", os problemas cognitivos iriam diminuir. Isso, porém, não aconteceu, conforme as pesquisas realizadas em 2001 de Elisabeth Bowen, juntamente com as pesquisas de Sean O'Faolein e de Erping Zhu e outros citados, como Carr, 2011, que afirma que leitores de hipertextos demoraram mais tempo para ler uma história. A atenção é dirigida para o maquinário de hipertexto e suas funções, em vez de ser para o tema próprio de que trata o texto. Mail e Dobson (apud CARR, 2010, p. 177) afirmam que "Muitas características do hipertexto resultam em acréscimo da carga cognitiva e assim podem ter exigido uma capacidade da memória de trabalho que excedia as possibilidades 
dos leitores". Resumindo as discussões e contrastando com Landow e Delany (1991), o hipertexto, segundo Carr (2011), tem uma carga cognitiva excessiva. Tal carga sobrecarrega o cérebro ao não permitir que se aprofunde nas limitações do próprio cérebro, de acordo com as ciências neurocognitivas.

Para que não haja desorientação do leitor e para que a memória de trabalho seja eficiente, o material de hipertexto deve estar bem organizado e bem localizado, como afirmaram Moser, Santos e Corcini (2016). Ao mesmo tempo em que oferece instantaneidade e imensidade de informações e que torna o leitor, como afirma Xavier (2005), cidadão do mundo, também pode conduzir o leitor à dispersão denunciada por Olgária Matos (2006), que diz ser a mídia virtual uma comunicação rápida, veloz, que não permite ir até o âmago das questões. Em grande parte das vezes fica-se nas afirmações ligeiras sobre todos os assuntos. Basta que se abra um site interativo para ver como a grande maioria se posiciona.

Tanto a mídia informativa quanto a de entretenimento visam um público consumidor, dando a consumir também os seus valores: ideologia da facilidade, rapidez na captação da mensagem, confisco do tempo da reflexão dominam e passam a impregnar a cultura e a educação através da simbiose entre mídia e indústria cultural; ambas ocuparam o espaço deixado vazio pela falência dos ideais humanistas de educação no Ocidente (MATOS, 2006, p. 15).

Xavier avisa sobre a possibilidade da dispersão, ao passo que Olgária Matos (2006 p. 26) não apenas assinala como enfatiza a dispersão afirmando que as mídias produzem "confisco do tempo da reflexão", dos leitores, e a autora se referia à televisão, que mostra o máximo de dispersão e o mínimo de atenção. Se a televisão que exige o mínimo de atenção e de concentração e o máximo de dispersão impede-os que prestem atenção por longo tempo às aulas magistrais, podemos dizer que o mesmo acontece com o leitor da era digital diante dos envios não lineares e outros links dos hipertextos.

$\mathrm{Na}$ revisão de literatura sobre os Estudos comportamentais e de neuroimagem sobre multitarefa Cyntia Bailer e Lêda Maria Braga Tomich (2016) “[...] multitarefa pode ser mais do que apenas uma questão de fazer mais trabalho cerebral. Pode ser também uma questão de fazer o trabalho de forma diferente em adaptação à carga de trabalho dobrada [...]" (JUST; BUCHWEITZ, 2014, p.8,) o que significa que ao realizar mais de uma tarefa ativase menos as regiões do cérebro correspondentes, resultando em um desempenho menor. 
Just, Keller e Cynkar (2008) usaram fMRI ${ }^{5}$ para explorar o impacto da compreensão auditiva simultânea na atividade cerebral associada com uma tarefa de direção simulada. A situação multitarefa resultou num declínio significativo na acurácia da direção (apud BAILER e TOMICH, 2016).

Portanto, o hipertexto precisa ser estruturado sempre levando em conta a capacidade cognitiva dos alunos e observando o que nos ensina a neurociência a respeito da memória de trabalho e de outras capacidades cerebrais. Sem esquecer que a hipertextualidade deve ter aparência de liberdade de escolha para o aluno, porém deve ser algo controlado nos bastidores, pois só assim pode ser benéfica e permitir ao aluno manter o foco no que interessa ser aprendido.

\section{Considerações finais}

O objetivo destas considerações era mostrar como o hipertexto pode constituir um mediador eficaz para a aprendizagem, desde que seja considerada a capacidade cognitiva discente, sendo um poderoso auxiliar para os docentes. Para isso, apresentou-se brevemente em que consiste a natureza do hipertexto cuja estrutura traz recursos que favorecem a autoaprendizagem.

Após apresentar o conceito de mediação como processo de intervenção de um elemento intermediário numa relação, a relação deixa então de ser direta e passa a ser mediada por esse elemento. No caso, a mediação entre o aprendiz e o que deve ser aprendido. Consideraram-se as mediações semiótica, tecnológica e pedagógica.

Estabelecidos os conceitos de hipertexto e de mediação, tratou-se de hipertexto como excelente mediador para a aprendizagem constituindo um recurso a ser usado pelos docentes como meio para que os discentes realizem aprendizagem ativa. E esta se dará na medida em que estes tiverem o desejo de aprender.

Ao professor mediador cabe a tarefa de estimular nos seus alunos esse desejo e interesse, jamais esquecendo o que expõe Luc Ferry (2011, 2012a, 2012b): o interesse nasce do esforço. Sem este não haverá aprendizagem. Somos uma inteligência a serviço da vontade.

\footnotetext{
${ }^{5}$ fMRI = Functional Magnetic Ressonance Imaglng (imagem por ressonância magnética funcional).
} 


\section{Referências}

BAILER, C.; TOMITCH, L. M. B. Estudos comportamentais e de neuroimagem sobre multitarefa: uma revisão de literatura. Alfa, rev. Linguíst., São José Rio Preto, v. 60, n. 2, may./aug. 2016. Disponível em <http://dx.doi.org/10.1590/1981-5794-1608-8>. Acesso em: 03 jun. 2018.

BARBOSA, C. BULHÕES, J. ZHANG, Y.; PEDRO, L. Media Multitasking: how does it affect learners and learning? In: Better e- Learning for Innovation in Education. ILIN, G. et al. Istambul: Özkaracan, 2017. p. 79-105.

CARR, N. (2010). The shallows: How the internet is changing the way we think, read and remember. New York: Atlantic Books, 2010.

CARR, N. O que a Internet está faz̧endo com nossos cérebros. A geração Superficial. Rio de Janeiro: Agir, 2011.

CASTELLS, M. A Galáxia da Internet. Rio de Janeiro: Zahar, 2003.

COPLESTON, F. History of Philosophy. Volume 2: Medieval Philosophy. EUA: Doubleday, 2003.

DESCARTES, R. Les Principes de la Philosopbie. In: DESCARTES. Oeuvres et Lettres. Paris: Gallimard, 1953.

DRISCOLL, M. P. Psychology of Learning for Instruction. Boston: Allyn and Bacon, 1994.

EDELMAN, G. La Science du Cerveau et la Connaissance. Paris: Odile Jacob, 2007.

FERRY, L.; VINCENT, J.-D. O que é o ser humano? Sobre os princípios fundamentais da filosofia e da biologia. Petrópolis: Vozes, 2011.

FERRY, L. O Anticonformista: Uma autobiografia intelectual. Rio de Janeiro: Difel, 2012a.

FERRY, L. A Revolução do Amor: Por uma espiritualidade laica. Rio de Janeiro: Objetiva, 2012b.

GILSON, E. La philosophie au Moyen Age, des origines patristiques à la fin du XIVe siècle. Deuxième édition, revue et augmentée. Paris : Payot, 1944.

GOFRON, B. School in the Era of the Internet. Educ. Educ. v. 17, n. 1, p. 171-180, 2014.

JUST, M. A.; BUCHWEITZ, A. What brain imaging reveals about the nature of multitasking. In: CHIPMAN, S. (Ed.). The oxford handbook of cognitive science. New York: Oxford University Press, 2014.

JUST, M. A.; KELLER, T. A.; CYNKAR, J. A. A decrease in brain activation associated with driving when listening to someone speak. Brain Research, Amsterndam, n. 1205, p. 70-80, 2008

KANDEL, E.; SQUIRE, L. Memoria: Da mente às moléculas. Porto Alegre: Artmed, 2003.

LANDOW, G.; GEORGE, P. Hypertext: the convergence of contemporary critical theory and technology. Baltimore: John Hopkins University Press, 1992. 
LANDOW, G. DELANY, P. Hypermedia and Literary Studies. Cambride: MIT Press, 1991.

LANDOW, G. P. Teoría del Hipertexto. Barcelona: Paidós, 1997.

LAUFER, S. Texto, Hipertexto, Hipermedia. Lisboa: RES Editora, 1993.

LEBRUN, M. Expérience esthétique et développement cognitif par la «réponse» à la littérature de jeunesse. Repères, Lyon, n. 13, p. 69-84, 1996.

LE COADIC, F. A Ciência da Informação. Brasília: Briquet, de Lemos, 1996.

LÉVY, P. As tecnologias da inteligência: o futuro do pensamento na Era da Informática. Rio de Janeiro: Ed. 34, 1996.

LÉVY, P. Cibercultura. São Paulo: Editora 34, 2008.

LEWIS, R.; SPENCER, D. What is Open Learning? Londres: Council for Educational Technology, 1986.

MATOS, O. C. F. Discretas esperanças: reflexões filosóficas sobre o mundo contemporâneo. São Paulo: Nova Alexandria, 2006.

MATTELART, A.; MATTELART, M. História das teorias da comunicação. São Paulo: Edições Loyola, 2007.

MAYER, R. E. Learning. In: MITZEL, H. E. (Ed.). Encyclopedia of educational research. New York: Free Press, 1982.

MCLUHAN, M. Os meios de comunicaşão como extensões do homem. São Paulo: Cultrix, 1996

MONTEIRO, S. D. As linguagens e o hipertexto: Uma introdução às possibilidades discursivas na forma hipertextual. Disponível em < http://www.pucsp.br/ cimid/8inf/monteiro/linghipe.pdf > Acesso em: 01 set. 2016.

MOSER, A.; SANTOS, N.; CORCINI, L. F. Neuro-Epistemological Aspects of Digital Hypertext as a Mediator Learning. IOSR Journal of Research \& Method in Education, v. 6, issue 6, p. 01-07, nov./dec. 2016.

OLIVEIRA, M. R. N. S. Do mito da tecnologia ao paradigma tecnológico: a mediação tecnológica nas práticas didático-pedagógicas. 24a Reunião Anual da ANPEd, Caxambu (MG), outubro de 2001.

OLIVEIRA, M. K. Vygotsky. In: TAILLE, Y. ; OLIVEIRA, M. K.; DANTAS, H. Piaget Vygotsky, Wallon. São Paulo: Summus, 1992.

OLIVEIRA, M. K. Vygotsky: aprendizado e desenvolvimento, um processo sócio histórico. 4. ed. São Paulo: Scipione, 2002.

PIPER, F. K. A importância da memória de trabalho para a aprendizagem. In: XIII Semana de Letras, 2014, Porto Alegre. XIII Semana de Letras: \#letrasnomundo, 2013. Disponível em $<$ http://ebooks.pucrs.br/edipucrs/anais/XIII_semanadeletras/pdfs/francielipiper.pdf > Acesso em 11/06/2018. 
POLANYI, M. The tacit dimension. Routledge \& Kegan Paul, London, 1966

SHECHTMAN, S. Mediação Pedagógica em ambientes virtuais de aprendizagem a partir da complexidade e do pensamento ecossistêmico. Dissertação (Mestrado em Educação) - Universidade Católica de Brasília, Brasília, 2009.

UNCAPHER, M. R., THIEU, M. K \& WAGNER, A. D. Media multitasking and memory: Differences working memory and long-term memory. Psychomic and application \& Review, v. 23, n. 2, p. 483-490, 2015. Disponível em: <http//link.springer.com/article/10.375\%2Fs13423-015-09073>. Acesso em: 11 nov. 2017.

VIGNAUX, P. Philosophie au moyen âge précédé d'une Introduction nouvelle. Albeuve : Castella, 1987.

VYGOTSKY, L. S. Internalização das funções psicológicas superiores. In: A formação social da mente: o desenvolvimento dos processos psicológicos superiores. Orgs. M. Cole, et al. Trad. J. Cipolla Neto. 4. ed. São Paulo: Martins Fontes, 1991.

XAVIER, A. C. Leitura, texto e hipertexto. In: MARCUSCHI \& XAVIER (orgs). Hipertextos e Gêneros Digitais. $2^{a}$ ed. Rio de Janeiro: Lucerna, 2005. 